\author{
Ana Galimberti \\ IAPCH-UNVMaría \\ Argentina
}

\title{
La salvación por la belleza: La obra de F. Dostoievski
}

\section{PRELIMINAR}

El universo narrativo de Dostoievski sorprende aún hoy por la complejidad y tensión argumentativa, por la sobreabundancia de personajes, encuentros y diálogos aparentemente ordinarios y, simultáneamente, por la recurrencia sostenida de ciertas ideas cuyos núcleos nocionales podrían sintetizarse en las siguientes cuestiones: la existencia de Dios y la inmortalidad del alma, por una parte, y la necesidad intrínseca, en el hombre, de pertenecer a una filía, una fraternidad que lo asuma y trascienda. Se sabe que el proyecto inicial del novelista ruso fue escribir una única y gran obra intitulada "El Ateísmo", proyecto que no lleva a cabo puntualmente pero que encuentra realización en sus grandes novelas: Crimen y Castigo (1866), El Idiota (1867), Demonios (1872) y Los hermanos Karamazov (1880). En efecto, las cuestiones señaladas constituyen el trasfondo metafísicoreligioso que nutre estas obras según dos niveles de reflexión suficientemente imbricados en los relatos; hablamos de la dialéctica discursiva que despliega el tratamiento de la voluntad de poder como núcleo constitutivo del hombre moderno, por una parte, $\mathrm{y}$, por otra, de la realidad y eficacia del mensaje johánico el cual anuncia la Redención de toda la humanidad a través del sello espiritual de lo humano en el hombre. Este núcleo "divino-humano" o teandrico destaca en la novelística de Dostoievski la existencia de un pórtico real que en todo hombre da acceso a su unidad originaria y misteriosa. Esto explica la insistencia del escritor ruso -honestamente preocupado por el nihilismo que atraviesa su siglo- en señalar una y otra vez cómo es posible para el hombre decidir desde su libertad la realización de dos vías ontológicamente opuestas: la transgresión más radical de su cualidad más específica: la divina-humanidad que lo con-figura como un proprium que se integra solidariamente a la totalidad de lo viviente; o, por lo contrario, su recepción y aceptación a través de la vía larga de lo humano, el sufrimiento que despoja al hombre del lastre material y lo orienta en un camino de des-asimiento hacia sí mismo.

En este sentido, puede comprenderse la narrativa de F. Dostoievski como una decidida y vigorosa denuncia semántica, y por esto mismo profundamente espiritual y grave, del nihilismo que atraviesa su siglo y se proyecta, como quiere Nietzsche, sobre los siglos venideros. 
Proponemos así un recorrido textual según tres instancias gradualmente complementarias: en primer lugar, el tratamiento de una fenomenología del mal que intenta mostrar el riesgo espiritual del hombre librado a sí mismo, separado de toda alteridad, el hombre intramundano, entronizado en un subjetivismo idólatra. El análisis de esta fenomenología del mal -aparentemente sin relación alguna con la experiencia de la belleza entendida esta desde la perspectiva de la novela europea décimonónica- apunta a espigar en algunos textos prerrogativos la consistencia y densidad de ciertas situaciones límites que arrastran consigo el dislocamiento, el desarraigo y la desvinculación del hombre de sí mismo y del prójimo. En segundo lugar, se tratará lo que hemos denominado núcleos o islotes de luminosidad en esta narrativa, representados por personajes y situaciones que indican la certeza de un punto de retorno, para el hombre, en el descenso, una nada sobreabundante de luz, desconocida y posible de asumir si el hombre acoge su naturaleza real; y, por último, la recapitulación de ambas instancias en lo que hemos denominado experiencia de la belleza. Este último punto advierte acerca de la naturaleza estéticoontológica de esta novelística, por encima de los subgéneros "novela psicológica", "policial" o "político-teológica" como muchas veces se la califica.

\section{UNA FENOMENOLOGÍA DEL MAL}

La clave significativa de la totalidad de la narrativa de Dostoievski se halla en una obra aparentemente menor si la comparamos con el impacto que tuvieron en la cultura rusa y europea sus grandes novelas (Crimen y Castigo, El idiota, Los hermanos Karamazov), hablamos de Memorias de subsuelo la cual constituye un verdadero prólogo para la moral del superhombre, a la que ilustra acabadamente, así como núcleo germinativo de todos y cada uno de los personajes que la representan según una diversidad de perspectivas y complejidad raras veces superada. Por otra parte, este libro es, también, el topos que el autor dibuja como el espacio abismal de impulsos e instintos que se hallan a la base de una katábasis psicológico-espiritual encubierta por la máscara nihilista de la "moral superior". El hombre del subsuelo es, en este caso, un burócrata mediocre cuyo rasgo fundamental es la hiperconciencia y la lucidez extrema de su degradación:

“...mi delicia provenía en que conservaba la conciencia demasiado lúcida de mi degradación, en que comprendía que había alcanzado el fondo de la infamia; que aquello era infame pero que no podía ser de otro modo..." (1).

A los atributos ya señalados, se agrega el carácter abstracto de sus afirmaciones, como si lo suyo no fuera lo propio sino el resultado de una observación correspondiente a un objeto exterior. Este rasgo identifica la tipología enferma de los

(1) DOSTOIEVSKI, Fedor. Obras completas, trad. Introd. y notas R. Cansino Sáenz, Madrid, Aguilar, 1946, $\mathrm{t}^{\circ} \mathrm{I}$ (Memorias de subsuelo) p. 1277. En adelante mencionaremos esta edición como OC con título y paginación correspondientes. Las cursivas, en todos los casos, salvo indicación sic, nos pertenecen. 
grandes violentos de la obra de Dostoievski lo cual, por otra parte, señala de manera reiterada y desde ángulos de complejidad diversos el núcleo enfermo del hombre moderno, su quiebra espiritual. En este sentido podemos adelantar -y se irá señalando cada vez- que la narrativa de Dostoievski es un discurso alusivo a esta quiebra espiritual en registro doble: por una parte, la crítica lúcida e írrita al cientificismo de su época, con las consecuencias previsibles de un punto de no retorno inviscerado en la idolización de la razón y, por otra y al mismo tiempo, la posibilidad siempre abierta para el hombre de descubrir en la mayor tragicidad de su descenso un núcleo constante, luminoso y nutricio dispuesto a acogerlo e impulsarlo hacia su renovación definitiva.

El esquema existencial de inteligibilidad del mundo para este hombre del subsuelo es -iy no podía ser de otro modo!- binario el cual coloca toda conducta humana en una falsa alternativa: inteligencia-inercia o instinto-acción, condenando a priori toda inteligibilidad a la parálisis y toda acción a la inmoralidad y el crimen. Aquí reconocemos, anticipado, el vitalismo nihilista de Nietzsche y el credo criminal de la voluntad de poder. Sin embargo, esta estructura binaria es un sofisma altamente calificado para la inteligencia contemporánea. Elaborado como crítica a un racionalismo extremo y sin alternativas que condena a Europa y a todo Occidente a un progresismo an-ético y des-ontologizado, la estructura de la novela dostoievskeana denuncia la muerte de la razón atrapada en sus propios esquemas discursivos, intentando sobrevivir en la positividad del miedo y la cobardía. La alternativa es un vitalismo a ultranza manifiesto en todas sus posibilidades, desde las más concretas a las más abstractas, cuyas únicas leyes son la autoafirmación egótica y el deseo creciente de transgresión frente a todo límite. Aquí se anticipa la debilidad infatuada de Rodian Raskolnikov (Crimen y Castigo), el poder destructivo de Stavroguin y Kirillov (Demonios) y la energía devoradora de los Karamazov. Conviene recordar las palabras esclarecedoras del célebre estudio de Romano Guardini sobre Dostoievski: "Kirillov y Stavroguin junto con la figura de Ivan Karamazov constituyen la expresión más perfecta dentro de la obra de Dostoievski, de la destrucción, la enfermedad y el mal" (2).

En efecto, Rodian Raskolnikov, estudiante universitario protagonista de Crimen y Castigo, cuyos rasgos caracterológicos más sobresalientes son el egocentrismo y el orgullo exacerbados, elabora a favor de un resentimiento social y existencial a la vez, una cierta teoría de la transgresión con la que intenta justificar el ejercicio pleno de la voluntad de poder sin límites. Se trata de uno de los pseudointelectuales en quienes se encarna el rostro de la ratio moderna, quien gusta analizarlo todo, en especial la vida humana en la que distingue dos clases de hombres: los ordinarios o esclavos, destinados al cumplimiento natural de la reproducción de la especie y a la continuidad servil del orden institucional recibido y los extraordinarios, aquellos que tienen "derecho a cometer toda clase de crímenes y a infringir de todas maneras las leyes, por el hecho mismo de ser extraordinarios" o según otra explicación "tienen derecho -claro que no un derecho oficial- a autorizar a su conciencia a saltar por encima de ... ciertos obstáculos y únicamente en el caso de que la ejecución de su designio así lo exigiere"

(2) GUARDINI, R. El universo religioso de Dostoievski, Bs.As., Emecé, 1954, p. 174. 
(3). El estilo cauteloso de esta última precisión subraya el gusto por el ejercicio de la argumentación dialéctica propio de la patología existencial de Raskolnikov, representante emblemático -inicia la línea de los razonadores que encontrará acabamiento en la figura de Iván Karamazov- de la patología del mundo moderno. Es importante, sin embargo, señalar dos hechos o, mejor, dos confesiones llevadas a cabo por Rodian Raskolnikov: la primera, bajo la forma de una explicación dada a Porfirio Petrovich, jefe de policía encargado de la investigación del crimen de dos ancianas perpetrado por el joven estudiante en un ejercicio pseudodelirante de su voluntad de poder, un crimen que de resultar perfecto le probaría su pertenencia a la estirpe de los hombres extraordinarios y justificaría en el límite no solo su acción sino lo originariamente insospechado por él, su culpabilidad.

La segunda confesión realizada a Sonia Simonovna, una muchacha que acaba de conocer y cuyas palabras - ¡las propias!- le revelan la insondabilidad de su orgullo al mismo tiempo que una necesidad desconocida de contarlo todo. En efecto, Raskolnikov desconoce el vigor insospechado de su culpabilidad que se está abriendo paso dificultosamente a través de las napas raciocinantes de su intelecto. Sus palabras frente al Otro lleno de piedad le entregan una imagen de sí mismo cínica e infatuada que lo exponen al desnudo:

“..jes que yo maté a la vieja? Yo me maté a mí mismo y a la vieja la mató el diablo" (4).

Es esta la primera vez que en el protagonista comienza a vislumbrarse, sin siquiera percibirlo él mismo, un espacio nuevo, una distancia que expone la totalidad de su existencia en su dimensión trágica, insospechada para una interioridad viciada por el ejercicio exclusivo de una inteligencia dialéctica al servicio de la voluntad de poder. Anticipo, no obstante, aunque velado, de un itinerario de conversión que tendrá lugar mucho tiempo después, en la cárcel siberiana.

Una teoría semejante por lo fuertemente dialéctica y rayana en el delirio biológico-trascendentalista es la que sostiene uno de los personajes de Demonios, Kirillov, estudiante universitario también él con rasgos caracterológicos muy próximos a Raskolnikov: ensimismamiento egocéntrico y frecuente malhumor. No obstante es preciso subrayar un rasgo propio de Kirillov -menguado aunque igualmente presente en el protagonista de Crimen y Castigo- hablamos de su amor por los niños y su sensibilidad abierta al sufrimiento del prójimo, rasgos distintivos, por otra parte, del hijo menor de los Karamazov, Aliosha. Presenta asimismo una semejanza con el príncipe Mischkin, protagonista de El Idiota en cuanto que experimenta en ciertas ocasiones una exultación interior que lo arroja a un cierto éxtasis temporal:

"K -Hay minutos, tiene uno minutos en que, de pronto se detiene el tiempo y se hace eterno..." (5).

(3) DOSTOIEVKSKI, ob. cit., II, p. 1253.

(4) Ob. cit., I, 1617

(5) Ob. cit., II, Demonios, p. 239. 
“K -Hay segundos, solo se dan cinco o seis segundos, en que de pronto siente Ud. la presencia de la eterna armonía, completamente lograda; no es cosa terrenal. No quiero decir que sea celestial sino que el hombre, en su forma terrenal no puede soportarla. Necesita transformarse físicamente o morir ... En esos cinco segundos he vivido yo una vida, y por ellos daría mi vida toda, porque lo valen" (6).

En el caso de Kirillov no hay mención a ninguna enfermedad, como sí ocurre en el personaje de El Idiota, salvo la indicación de que "hablaba a saltos, incurriendo en faltas de gramática como si perdiese el hilo y se embrollase, en cuanto se metía a hacer una frase algo larga" (7). Con estos rasgos caracterológicos -que hablan ciertamente de un desorden profundo- Kirillov elabora una teoría de la voluntad de poder identificada con el libre albedrío que es una variación de la teoría esgrimida por el hombre del subsuelo, pero en clave político-teológica a diferencia de la de Rodian Raskolnikov cuya base es solamente la justicia intramundana. Las palabras de Kirillov son un anticipo casi literal de muchas páginas nietzscheanas. El extracto que sigue entrega en el núcleo su pensamiento:

Yo no puedo pensar en otra cosa, y toda mi vida me la paso pensando en una sola cosa. A mí Dios me ha atormentado toda la vida ...

Dios es el dolor del miedo a la muerte. Quien venza el dolor y el miedo, ese será Dios. Entonces empezará una nueva vida, entonces existirá el hombre nuevo, todo será nuevo... Entonces, la historia se dividirá en dos partes: del gorila al aniquilamiento de Dios y del aniquilamiento de Dios ... al cambio de la tierra y del hombre físico (8).

A la libertad personal y superioridad del hombre extraordinario esgrimidas por Raskolnikov -la moral de superhombre nietzscheano- se sustituye en Kirillov la dialéctica de la inexistencia de Dios y la libertad personal. Por otra parte, ya no se trata tanto de justificar transgresiones sino de llevar a cabo definitivamente la única transgresión, aquella que legitima todas las otras y arrastra consigo la definitiva y verdadera libertad para el hombre. Se trata, en suma, de una dialéctica que se perfecciona en argumentaciones cada vez más sofisticadas a la búsqueda de una hipóstasis a la insoluble cuestión de la existencia de Dios. La complejidad y extensión del razonamiento de Kirillov se concentra en lo que podríamos denominar su "teoría del suicidio", a la que dedica todo un capítulo (9), leitmotiv de emergencias constantes a través de una larga ruminación mental que irá confirmando en el personaje su itinerario hacia el acto final. El siguiente texto recoge de manera relativamente breve un último estadio de su teoría, en una síntesis admirablemente clara:

"K- Yo estoy obligado a pegarme un tiro porque en eso radica la plenitud de mi libre albedrío... en matarse uno mismo.

\footnotetext{
(6) Ibídem

(7) Ibídem, p. 158.

(8) Ibídem, pp. 172-173

(9) Parte III, cap. III.
} 
P- Pero mire que no es Ud. el único que se suicida; se suicidan otros muchos.

K- Con una causa. Pero sin causa ninguna, sino simplemente por su voluntad..., solo yo

P- ¿Sabe Ud. una cosa? ... yo en su lugar, en vez de matarme a mí mismo para demostrar mi independencia, mataría a otro...

Q- ¿Matar a otro..? ... Yo no soy tú. Yo quiero el punto más alto, y me suicido. ...

Yo estoy obligado a declarar mi incredulidad. Para mí no hay idea más elevada que la de que Dios no existe. De mi parte tengo la historia humana. El hombre sólo inventó a Dios para vivir sin suicidarse: en esto consiste toda la historia universal hasta hoy. Yo solo en toda la historia universal, no he querido por primera vez inventar a Dios. Que lo sepan de una vez para siempre!” (10).

Kirillov quiere, así, aprehender el fundamento mismo de la existencia humana y este propósito y voluntad enferma lo conducen a su propio fin. Pero todavía hay algo más sorprendente en la constitución magistral de este descenso psicológicoespiritual de Kirillov, hablamos de la bestialización que se opera en él momentos antes de su muerte. Este hombre cuya finalidad era promover una mutación físicoespiritual de la especie a partir de la probatoria letal de la muerte del Dios "antiguo", este hombre antes de morir, retrograda a una forma animal, una bestia agazapada que pierde la articulación del lenguaje y que en un grito inarticulado y desgarrador se lanza contra aquel que no es sino el móvil próximo de su acto suicida: un rugido horrible, una furia bestial, y un mordisco fuerte y desgarrador de la carne, son el preludio desesperado de este suicidio. "Del gorila al gorila" podría intitularse irónicamente el grotesco cuadro final.

Nikolai Stavroguin, inspirador de la tríada demoníaca, de quien R. Guardini dice que "la raigambre del mal es definitivamente mayor que en Verjovenskii" (11) es el leader intelectual de Kirillov y Schátov. Stavroguin pertenece a la estirpe de los grandes enfermos espirituales de Dostoievski cuya descripción más generalizada la da el mismo narrador de Demonios al caracterizar, de un trazo, al hombre moderno:

"temperamento nervioso, atormentado y desdoblado de los individuos de nuestro tiempo..." (12)

Se acentúan en Stavroguin los rasgos de Raskolnikov y Kirillov. En efecto, se trata de un discípulo de Verjovenskii en quien la filiación se ha perfeccionado hasta el límite; a los rasgos de ensimismamiento y abstracción típicos, se acumulan otros, como el de una distinción general, un cinismo devorador y una particular y fría complacencia en la perversión y distanciamiento ejercidos, simultáneamente, en toda relación con el otro, incluida su propia madre. Se agrega a esto su particular

(10) DOSTOIEVSKI, F. O.C., II, pp. 451-452.

(11) GUARDINI, R. Ob. cit., p. 210.

(12) DOSTOIEVSKI, F. O.C., II, p. 222. 
fuerza física, cuya contención habitual no disimula un temperamento iracundo que en "un rapto de ira habría matado con plena conciencia sin perder en absoluto la serenidad" (13).

Hay, asimismo, un punto de particular coincidencia entre Kirillov y Stavroguin. Se trata de una conducta intempestiva de bestialización que en Kirillov caracteriza un momento terminal en el descenso mientras que en Stavroguin tipifica una especie de mecanismo propio, constante, intrínseco a su cinismo y cuya presencia se hace sentir más allá de las apariencias de distinción y serenidad exteriores:

"Vivió entre nosotros medio año ... indolente, pacífico, bastante adusto... pero pasaron algunos meses y la fiera enseñó de pronto sus garras"

...

Advertíase que tenía algo vago, misterioso que ella misma [su madre] no podía decir, y muchas veces de soslayo y atentamente, poníase a mirar a Nikolai imaginando y pensando quien sabe qué ... y he ahí que de pronto la fiera enseñó sus garras” (14).

Los escándalos que se siguen, producidos por Stavroguin en el medio social de su madre, confirman precisamente este mecanismo: hablamos de la literalidad con que traduce la expresión que un antiguo miembro de la tertulia social gusta repetir a fin de subrayar su autonomía de criterio: “¡No, lo que es a mí no me conducirán de la nariz". Y he aquí que es esto lo que hace intempestivamente Stavroguin: retorcerle furiosamente la nariz en público (15). Al pedido de explicaciones que algunos días después le formula su pariente, el gobernador, el personaje que ha sido definido antes como un ejemplo de serenidad, frialdad y dominio de sí, le clava "enérgicamente los dientes en la parte superior de la oreja" (16).

Que este rasgo de bestialidad feroz sea potencialmente constitutivo de Stavroguin configura -dice R. Guardini- "un hecho destructor, disolvente, una amenaza a la vida de la persona humana. Cuando el animal nace en el hombre, nace asimismo el peligro de sucumbir al impulso de las fuerzas infrapersonales y telúricas" (17). En efecto, esta serie de escándalos de Stavroguin pone de manifiesto una conducta delirante gratuitamente destructiva, de infatuación y orgullo extremos. Pero aquí no se trata de una retrogradación o alienación psicológica operada en el límite mismo de la existencia, como en el caso de Kirillov o de neurosis ambivalente como en Raskolnikov, sino más bien de su extremo opuesto aunque simétricamente complementario, de distanciamiento y curiosa frialdad frente al otro; curiosidad solo aparente ya que el fundamento profundo de su actitud es una indiferencia perversa en constante transformación. La síntesis que el mismo Schatov hace de Stavroguin, en un reproche doloroso, cierra este dibujo acabado del mal bajo la especie espiritual del sofista:

(13) Ibídem

(14) DOSTOIEVSKI, F. O.C., II, p. 130.

(15) DOSTOIEVSKI, F. O.C., II, p. 132.

(16) DOSTOIEVSKI, F. O.C., II, p. 194.

(17) GUARDINI, R. Ob. cit., p. 221. 
"En América dormí tres meses en un montón de paja al lado de un desdichado ... por él supe que por el mismo tiempo que Ud. implantaba en mi corazón a Dios y la patria, acaso por aquellos mismos días había Ud. envenenado el corazón de Kirillov... Ud. corroboró en él el error y la calumnia y llevó su razón hasta la locura..." (18).

Abordemos ahora la figura de Iván Karamazov. Su filiación en la estirpe que estamos describiendo no ofrece dudas: operan en él, por una parte, la desoladora energía karamazovesca y, por otra, una constructividad discursiva que lo vuelven no solo "maestro" de Smerdiakov sino autor de dos discursos internos que atraviesan toda la obra, hablamos del artículo sobre la justicia eclesiástica y de la leyenda del Gran Inquisidor que él mismo narra a su hermano menor. Ahora bien, más allá de las características especulativas del personaje -que en esto reencuentra a Raskolnikov, Kirillov y Stavroguin- la tenebrosidad que lo habita y va ganando paulatinamente, obedece a un propósito de destrucción fontal con el que cumpliría acabadamente su declaración reiterada de ateísmo. En efecto, de lo que se trata profundamente en Iván Karamazov es de consumar -por la mediación de su hermano bastardo y en la persona de su padre- la destrucción, para la naturaleza humana, de la eficacia operativa del símbolo del Padre. Es un parricidio originario el que propone, una variante teológica, si se pudiera hablar así en novelística, de la "teoría" del hombre nuevo de Kirillov. Y son las categorías mismas del texto las que facilitan tal afirmación, ya que de otro modo no se explican el "desdoblamiento" de Iván Karamazov -que él mismo niega, al exclamar: “¡Esto no ha sido un sueño! No, juro que no ha sido un sueño que todo esto ha sido realidad" (19), refiriéndose a la presencia del diablo en su propio cuarto- ni la ambigüedad con la que el narrador trata, a lo largo de todo este breve capítulo, el supuesto trastorno cerebral diagnosticado a Iván. En suma, Dostoievski articula, una vez más, en este personaje, el develamiento de las fuerzas oscuras en el hombre, a través de una de sus máscaras preferidas: la abstracción discursiva. Signo premonitorio, para Dostoievski, de una modernidad progresista que ha sumido a Europa en el nihilismo y el desorden político bajo la máscara sofisticada de la razón científica.

\section{LOS NÚCLEOS DE LUMINOSIDAD}

En el horizonte de descenso personal como presencia indiscutible del mal en el hombre y el mundo, se destaca en el relato dostoievskeano núcleos de luz que emergen, precisamente, desde esta abismación, como si la luminosidad del espíritu no fuera posible para el hombre moderno sino como experiencia de dolor y sufrimiento extremos. Todo ocurre como si la civilización moderna hubiera llegado a un punto de desarrollo en el cual la afirmación del sujeto hubiera agotado toda respuesta de búsqueda personal produciéndose en él la aniquilación del Espíritu. Importa

(18) DOSTOIEVSKI, F. O.C., II, p. 246.

(19) DOSTOIEVSKI, F. O.C., II, p. 1284. Cf. la totalidad del cap. IX, parte IV. 
subrayar, en esta instancia, la profunda religiosidad del autor ruso a quien suele presentarse como escindido entre dos polos: el socialismo progresista de sus años de juventud y la religiosidad crística que sigue a sus años de cárcel. La dimensión religiosa que nutrió su vida toda y transmitió a través de su novelística no fue posterior al hecho biográfico de su encarcelamiento y condena a muerte, como suele afirmarse muchas veces -aun cuando ambos motivos son recurrentes en su relato y han sido determinantes, indudablemente, del conocimiento del pueblo ruso, en estratos a los que de otro modo no hubiera podido acceder- sino que esta dimensión religiosa fue constitutiva de una personalidad que reclamaba una fraternidad universal, fundada en un amor que rescatara, en el hombre, a la persona. De aquí que sus protagonistas se debatan entre un socialismo progresista colectivo, un individualismo neurótico e infatuado y un reconocimiento crístico renovador. Las siguientes palabras de Nicolas Berdiaeff a propósito de Demonios, en uno de los estudios más lúcidos sobre Dostoievski, esclarecen acerca de esta cuestión: "Mais telle qu'elle est, l'utopie de Versilov est intéressante en ce qu'elle développe les idées de Dostoievski sur l'amour. L'humanité athée doit aboutir à la férocité, à l'entre'égorgement; elle doit ramener l'homme à l'état de simple moyen. On aime son semblable en Dieu: un tel amour affermit en chaque être la notion de l'éternité; seul il est l'amour véritable l'amour chrétien, lié à l'immortalité de l'âme, affirmation de cette immortalité. Voilà la pensée essentielle de Dostoievski. L'amour véritable est lié à la personnalité, la personnalité est liée à l'immortalité de l'âme. Cela est vrai pour l'amour sexuel comme pour toute autre forme de l'amour humain. Il existe un autre amour qui s'adresse à l'homme au dehors de Dieu, qui méconnaît en l'homme l'aspect éternel, seul perceptible en Dieu, enfin qui n'est pas dirigé vers la vie éternelle. C'est un amour impersonnel, collectif, qui pousse les êtres à s'agréger les uns aux autres, afin qu'il leur soit moins effrayant de vivre, ayant perdu la foi en Dieu et en l'immortalité, c'est-à-dire dans le sens de la vie. Cet amour-là est le dernier terme de l'arbitraire humain et de l'affirmation de soi" (20).

Avancemos, ahora sobre, el punto propuesto. Dos son los personajes que reclaman nuestra atención, por su naturaleza y por la profunda continuidad y proyección que el autor establece entre ambos; hablamos del príncipe Mischkin y de Aliosha Karamazov.

Siempre hay un modo de escapar, dice Henri de Lubac (21), a la urgencia y tragicidad del drama espiritual. En efecto, la figura del príncipe Mischkin en $E l$ idiota podría ser correctamente explicada a partir de la patología que el título autoriza, y cuya descripción es lo suficientemente precisa, exhaustiva y pertinente como para merecer su cita entre especialistas de prestigio (22). Pero lo interesante de su caso es la permanencia, a partir de una estructura psicológica compleja y contradictoria, de ciertas actitudes y respuestas que descubren sin reticencias el espacio inocente del corazón del hombre. Es precisamente este rasgo el que permite hablar a la crítica literaria como de una tipología pura en Mischkin, si se lo compara con otros

(20) BERDIAEFF. L'esprit de Dostoievski, Paris, Stock, 1974, pp.159-160.

(21) DE LUBAC, H. Le drame de l'humanisme ahtée ${ }_{2}$ Paris, Spes, 1945, p. 330

(22) SZEKELI, Bela. Diccionario Enciclopédico de la Psique, Bs. As., Ed. Claridad, 1958, p.224. Cf. part. el artículo: "epilepsia", en donde aparecen citas textuales de El idiota y Crimen y Castigo. 
personajes dostoievskianos. Por otra parte, el autor logra a través de un procedimiento que suma al cuadro realista más inmediato -epilepsia congénita, cuatro años de internación en una clínica fuera de Rusia, estado de salud inestable si no desequilibrado a lo largo de la novela, existencia de una herencia, etc.- una expansión de sentido cada vez mayor aunque gradual que surge de relatos incluidos que el mismo Mischkin da a conocer. Son estos relatos los que abren un espacio posible de comprensión para el cuadro trágico del crimen final, anticipado, sin embargo, desde el comienzo de la obra. Veamos esto mismo, sumariamente y en sus elementos constitutivos:

1. La enfermedad: múltiples y complementarias son las descripciones del morbus sacer en El Idiota coincidentes, todas, en los siguientes rasgos: a) estupor y miedo ante la inminencia de la crisis; b) distracción generalizada y confusión de personas y cosas; c) hiperactividad intelectual, acompañada de hiperactividad verbal muchas veces, y siempre de incoherencia y alogicidad; d) sensación de extrañeza y separación ("¡aquella extrañeza me mataba!, $O C, \mathrm{I}, 1819$ ); e) tristeza extrema y "depresión espiritual" (sic, $O C, \mathrm{I}, 1926)$; f) acentuación gradual de la tenebrosidad en relación directa con la recurrencia de las crisis; g) ideas fijas y/o delirio (23).

Hasta aquí queda descrita una dinámica de minusvalía en el sujeto. No obstante, importa señalar en este punto, precisamente, una conjunción psicoespiritual que, en el caso de Mischkin y en orden a un cierto tipo de conocimiento, hace posible una percepción anticipada del nudo criminal que se incoa en la obra. En efecto, hay dos situaciones que se conjugan en él: por una parte, un estado de hipersensibilidad e hiperconciencia que la enfermedad dinamiza y que lleva al príncipe a una experiencia de júbilo esencial. He aquí el texto:

"Pensaba, entre otras cosas, en que en su estado epiléptico había un grado, casi inmediatamente antes del ataque [...] en que, de pronto, en medio de la tristeza, de la bruma, de la opresión espiritual, parecía a veces inflamársele el cerebro y un estallido extraordinario exaltar al mismo tiempo todas sus energías vitales. La sensación de la vida, la conciencia, casi se duplicaba en aquellos instantes que se prolongaban como relámpagos. Alma, corazón, iluminábanse con desusada luz; todas sus agitaciones, todas sus dudas, toda su inquietud parecían amansarse de pronto, sumirse en una altísima serenidad, henchida de júbilo, y unas ilusiones radiantes y armoniosas, llenas de razón y de razones definitivas ..." ...¿Qué importa que se trate de una enfermedad?..." decidió por último... que aquello era realmente "belleza y visión divi-

(23) Acerca de la proyección biográfica en este personaje la síntesis de R. Cansinos Sáenz la expresa con toda nitidez: "El idiota de la novela, el príncipe Liov Nicolayevich Mischkin, es una proyección del novelista mismo, tiene su misma enfermedad -la epilepsia, el morbo comicial y divino, signo en Oriente de los iluminados y profetas- y siente su erotismo sublimado en místico amor hacia toda la humanidad. [...] Dostoievski ha encarnado en él toda una ética, y ese "idiota" es nada menos que la réplica que él opone a esa otra figura proterva de Raskolnikov y a su filosofía despiadada del "hombre extraordinario". [...] Su lección ética es una lección práctica de bondad innata ... Mischkin no razona ... es un alma evangélica, un pobre de espíritu”. Cf. Introducción a $O C$, ed. cit., $\mathrm{t}^{\mathrm{o}} \mathrm{I}, \mathrm{pp} .1781-1782$. 
na", que aquello era "la suprema síntesis de la vida", de eso no podía dudar. Por lo demás, él no se aferraba a la parte dialéctica de su razonamiento, el estupor, la niebla mental, el idiotismo, eran para él la clara consecuencia de aquellos instantes... ¿qué hacer verdaderamente con la realidad? Porque aquello existía, él podía decirse a sí mismo, en aquel segundo, por una suerte ilimitada, que aquel segundo él lo sentía plenamente, y podía incluso valer por toda su vida [...] en ese momento se me hace comprensible esa frase extraordinaria de que "ya no habrá más tiempo" (24).

De acuerdo con esta descripción el instante previo a la crisis epiléptica dilata la capacidad cognoscitiva en un grado que el narrador define en términos de plenitud, luz, armonía y júbilo, cuyo dinamismo moviliza no sólo la capacidad raciocinante del sujeto sino la totalidad de la psyché. En un escritor como Dostoievski la yuxtaposición "alma, corazón" no es azarosa y parece aludir a una integración cierta entre razón raciocinante y razón cordial, hipótesis que el mismo texto confirma al calificar estas ilusiones como "llenas de razón, y de razones definitivas" (25). Por otra parte, Mischkin es el único personaje de Dostoievski en quien el amor es totalmente caridad y esto según una experiencia solidaria entre sentimiento, intencionalidad y comunicación al otro. En esto consiste, simultáneamente, su inocencia y su rareza, su alegría y su vulnerabilidad.

Ahora bien, este tipo de conocimiento que aparece como un estado de éxtasis previo a la patología tiene su correlato en el orden de la existencia normal, en una manifestación que podría definirse anticipadamente como un don de visión frente al sufrimiento, y que Mischkin posee; don que, ciertamente, se halla en relación directa con la fuerza de caridad intrínseca de su corazón. Ilustremos esto mismo desde una de las escenas iniciales de la obra, cuando el príncipe Mischkin se encuentra inesperadamente frente al retrato de una mujer que tendrá en la obra $-\mathrm{y}$ en la vida del príncipe- un papel protagónico. A la pregunta de su interlocutor: “¿Le gusta a Ud. esta mujer, príncipe?", este responde:

“- ${ }_{\text {¡Es }}$ un rostro prodigioso! ... y estoy seguro de que su destino no ha de ser vulgar ... Tiene la cara alegre y ha sufrido horriblemente, ¿no es verdad? Lo están diciendo los ojos, mire Ud... Es un rostro orgulloso, terriblemente orgulloso, y mire Ud.: no sé si será una mujer buena, ;Ah, si fuera buena! ¡Entonces, todo se habría salvado, seguramente!

...

“-¿Se casaría Ud. con una mujer así? -continuó ...

- Yo no puedo casarme con esa ni con ninguna mujer: soy un enfermo, dijo el príncipe.

- Y Rogochin, ¿se casaría con ella? ¿Qué opina Ud.?

- Casarse con ella, creo que mañana mismo; se casaría con ella, y luego, a la semana, la mataría” (26).

(24) DOSTOIEVSKI, F. O.C., I, p. 1928

(25) Ibídem.

(26) DOSTOIEVSKI, F. O.C., I, p. 1806 
El texto deja al descubierto la capacidad de visión del príncipe en la lectura del rostro de Nastasia Filippovna y en la anticipación del nudo trágico del relato que culminará con su muerte en manos de Rogochin. No se trata, en un escritor como Dostoievski, de un recurso de anticipación argumentativa sino de subrayar desde el comienzo el don de visión que asiste al príncipe, lo cual trasciende su situación de enfermo al mismo tiempo que orientará toda su conducta posterior. Es interesante observar cómo este don de visión o forma de conocimiento premonitorio procede en Mischkin a partir de la percepción de ciertos rasgos y de sus relaciones específicas, a saber: 1) belleza, sufrimiento, orgullo; 2) tragicidad implícita en la relación de tales elementos. Adviértase que a la última pregunta de su interlocutor, Mischkin responde no por el conocimiento que tiene de Rogochin -un personaje ocasional hasta entonces para él- sino desde la lectura interior del rostro de la mujer ausente; 3) la inconmensurable realidad del Bien que aparece como la única alternativa de salvación para tal tragicidad. El rostro del retrato guarda para Mischkin, un enigma: “ ¡Ah, si fuera buena!” se dice anhelante. Los polos que definen la síntesis de la mujer del retrato es Belleza y Bien, polos que aquí se ponen de manifiesto nítidamente, pero que pueblan el universo dostoievskiano en niveles diversos, subrayando cada vez el punto originario de una segura promesa de salvación para el hombre.

2. Relatos incluidos Uno de los recursos de la novelística rusa en general y de la de Dostoievski en particular es la expansión del relato central en narraciones que, vinculadas sin duda al núcleo argumentativo, lo abren y precisan en modalidades nuevas destinadas a una mayor comprensión. Destacamos en este punto tres relatos incluidos: el del sentenciado a muerte y absuelto a último momento, el de María y los niños y el de las historias de Iliuscha y los niños, y la historia de Markel. Veamos puntualmente cada uno de ellos: a) El del sentenciado a muerte y absuelto a último momento. Más allá de la proyección autobiográfica de este relato (27) lo importante es la recreación del tema de la esperanza que suscita y esto en tres registros que se complementan. El primero alude a la inexorabilidad de la ley escrita y su carácter inapelable; el texto permite, ciertamente, una lectura doble: natural y sobrenatural, destinada a subrayar la necesidad propia de lo humano del hombre:

"El asesinato en virtud de una sentencia es más espantoso que el asesinato que comete un criminal. Aquel a quien asesinan los bandidos, a quien degüellan de noche en un bosque o en algún otro paraje, espera salvarse hasta el postrer momento. Pero esta última esperanza que hace diez veces más ligera la muerte, te la quitan con ese "de fijo"; allí se trata de una sentencia, y en eso de que seguramente no has de poder rehuirla se cifra un tormento espantoso... Coja Ud. un soldado y colóquelo delante del mismo cañón y dispare sobre él; a pesar de

(27) Sus dos críticos más importantes, A. LEVINSON y H. CARR no sólo dan cuenta de este relato como un hecho real en la vida de Dostoievski sino que señalan reiteradamente que la conversión psicológico-espiritual de D. encuentra punto de partida definitivo en este minuto previo a la ejecución de la que fuera inesperadamente liberado gracias a una orden de clemencia del zar, llegada a último momento (citado por CANSINOS ASSENS, R. O.C., pp.. 27-28). En el desarrollo de este trabajo hemos emitido un juicio de reserva respecto de esta opinión, en el sentido de subrayar la religiosidad íncita ab origine en el espíritu de Dostoievski. 
todo no se perderá la esperanza por completo; pero léale Ud. a este mismo soldado la sentencia “fijamente” y o se volverá loco o se echará a llorar..." (28).

Lo evidente aquí es la relación proporcional entre la capacidad de sufrimiento y la esperanza; de aquí que se afirme que lo verdaderamente inhumano no sea el carácter punitorio, legal de la sentencia, sino el de su anuncio al condenado, el de su inexorabilidad. Esta primera versión se completa páginas más adelante con otro relato que no es sino un nuevo registro en la meditación y tiene que ver con el hecho "curioso" de una conmutación de pena inesperada. Una vez más, nos encontramos con la valoración del minuto previo a una experiencia límite; se trata, en efecto, de un símil del tiempo extático que precede a la crisis epiléptica y, en donde, a favor de la situación límite se reconoce, como en un relámpago, el valor sagrado de la vida. Se trata, en suma, de una aprehensión global y totalizadora de lo real, una forma de contemplación interiorizada del cosmos; en otras palabras, una experiencia religiosa:

"Llegó el momento en que sólo le quedaban cinco minutos de vida nada más. Contaba él que estos cinco minutos le habían parecido un espacio de tiempo infinito, de una riqueza enorme... No lejos de allí había una iglesia, y en la techumbre de la dorada cúpula refulgía al sol radiante. Recordaba haberse quedado mirando de hito en hito aquella cúpula y a los rayos del sol que en ella centelleaban; no podía apartar los ojos de aquellos rayos del sol, parecíale que aquellos rayos de sol fuesen para él una nueva Naturaleza...” (29).

Entre ambas versiones se interpone un relato breve, personal de la vida de Mischkin, que entrega la clave general del relato incluido en su totalidad:

“También, a veces, al mediodía... cuando te encuentras en algún sitio de la montaña y te hallas solo entre picachos, rodeado de pinos añosos, corpulentos, llenos de savia..., el sol radiante, el cielo azul, una quietud terrible. Entonces parece como que todo nos llama no sé adónde; y yo pensaba que yendo todo derecho, andando, andando, hasta llegar más allá de aquella raya donde tierra y cielo se unían, allí estaría la solución de todo e inmediatamente empezaría una nueva vida mil veces más potente que la nuestra... Siempre estaba soñando... ¡Sí, no soñaba yo poco! Y luego, parecíame que también en el presidio se podría encontrar una vida enorme" (30).

Lo sorprendente es no sólo la resonancia cósmica y su apelación a un horizonte otro, sino el contraste de la frase final que opone a la luminosidad y apertura del cosmos physico la oscuridad y clausura del presidio. Son estas frases -abundantes en la escritura del gran ruso- las que subrayan las ideas-fuerza del autor; en este caso, el carácter hondamente interior de la verdadera contemplación y el vínculo profundo entre culpabilidad, sufrimiento y expiación verdadera.

(28) DOSTOIEVSKI, F. O.C., I, p. 1798

(29) DOSTOIEVSKI, F. O.C., I, p. 1822.

(30) DOSTOIEVSKI, F. O.C., I, p. 1821. 
b) relato de María y los niños. Se trata de una historia autónoma, episodio de la vida de Mischkin que ocupa todo el capítulo VI de la primera parte de la novela. Surge, una vez más, en respuesta a una pregunta aparentemente trivial sobre el tema del amor humano. La respuesta del príncipe es directa y sirve de prólogo para la inteligibilidad de todo el relato: "Yo no he estado nunca enamorado. He sido feliz de otro modo" (31). Este modo de felicidad constituye el núcleo de la historia, la cual puede resumirse en sus articulaciones fundamentales, del siguiente modo: 1) connaturalidad del espíritu de infancia en Mischkin. El príncipe designa como felices los cuatro largos años pasados junto a un grupo de niños, en la pequeña aldea suiza en donde lo recluyera para su curación. Tal experiencia es expresada por Mischkin como un espacio de inocencia y cura del alma: los niños "curan el alma", dice, y refiere como "prueba" de tal afirmación la influencia decisiva del grupo de niños -su sola presencia- en la curación de un paciente de la clínica en la que él mismo se hallaba, y cuya única enfermedad consistía en "un terrible sufrimiento interior" (32). 2) unión de la inteligencia y el corazón en la experiencia infantil. Estar junto a los niños significó para el príncipe "hablar con ellos y poder contarles todo" (33); esta capacidad omnicomprensiva del conocimiento infantil parece incluir una particular docilidad a la verdad de las cosas; 3 ) piedad natural en el espíritu infantil. En este punto se incluye la historia de María, una joven tuberculosa, víctima inocente de su familia y de toda la aldea. "He sido feliz de otro modo", había dicho el príncipe. En efecto, su capacidad de visión ante el sufrimiento primero, y de compasión después, llevan al príncipe a demostrar a María su caridad a través del consuelo. La piedad del príncipe hace que todo el cuadro se transforme gradualmente: de las persecuciones y apedreadas iniciales que como en un "juego" los niños perpetraban contra la joven mujer, aquellos comienzan por saludar a María, luego le llevan comida y vestido y, por último -dice el relato- "algunos iban sencillamente para abrazarla, besarla y decirle: 'Je vous aime, Marie'” (34).

Si se tiene en cuenta que el núcleo argumentativo de El Idiota es, en términos lineales, la "rivalidad" amorosa entre Rogochin y Mischkin frente a Nastasia Filippovna, hacia quien el príncipe ha reiterado que solo lo une un sentimiento de piedad profunda, la historia de María y los niños ilumina doblemente la naturaleza de Mischkin: se trata, por una parte, de un verdadero espíritu de infancia, aquel que sólo respira y crece naturalmente en el vínculo generoso de la amistad, y, por otra, de una naturaleza para quien la misericordia es un connatural ejercicio del consuelo. De aquí su capacidad de visión anticipada respecto del dolor, su compasión extrema, su percepción directa del mal. Por lo demás, la historia de María y los niños ilumina la frase que Nastasia Filippovna dirige a Aglaya -la mujer niña, la mujer virgen, la mujer pura en la obra-: "Para mí es Ud. lo mismo que para él: la luz del alma... Ud. y él son para mí uno solo" (35).

Finalmente, y para cerrar esta enorme y bella imagen de lo humano en el hombre que es Mischkin, esta historia de María y los niños arroja nueva luz a la

(31) DOSTOIEVSKI, F. O.C., I, p. 1826.

(32) DOSTOIEVSKI, F. O.C., I, p. 1827.

(33) DOSTOIEVSKI, F. O.C., I, p. 1827.

(34) En el original Cf. DOSTOIEVSKI, F. O.C., I, p. 1828.

(35) DOSTOIEVSKI, F. O.C., I, p. 2072. 
gran escena de la Pietas final: Rogochin delirando en los brazos de Mischkin -él mismo definitivamente alienado y "fuera de este mundo"- junto al cadáver de Nastasia a quien han velado durante toda la noche.

c) historia de Iliuscha y los niños e historia de Markel. En el conjunto de la obra de Dostoievski, El Idiota podría ser considerada como la "historia del hombre nuevo" anunciada por el narrador en las últimas líneas de Crimen y Castigo y, al mismo tiempo, como la anticipación de instancias paradigmáticas hondamente cristianas que hallarán forma real en la persona y misión de Aliosha, el menor de los hermanos Karamazov. Podría agregarse, además, que la historia de Mischkin halla cierta continuidad en la conjunción de dos relatos breves incluidos en Los hermanos Karamazov -de los que casi no se habla- que explican, en nuestra hipótesis, la verdadera dimensión de la existencia de Aliosha y el vínculo originario que existe entre Belleza y Bien en la obra de Dostoievski. Se trata de la historia de Iliuscha y el grupo de niños, de su extraña enfermedad desatada, al parecer, por un acto de perversión cometido a instancias de Smerdiakov, y que cobra a los ojos del niño la dimensión de un crimen; y, finalmente, de su dolorosa e inexplicable muerte (36). Y de la historia de Markel, el hermano del starets Zósima, de su enfermedad, conversión y muerte en plena juventud y del signo que esta breve vida -que tardía pero hondamente descubre la existencia invisible de Cristo en el mundo- traza no sólo para la vocación monástica de Zósima sino también para la misión que este encargará a Aliosha Karamazov, su discípulo, mucho tiempo después. Todo ocurre como si Dostoievski frente a Mischkin, el más amado de sus personajes, hubiera decidido darle en Aliosha una existencia posible en el mundo, en la que el don de visión - propio de los monjes en la tradición ortodoxa- y el espíritu de infancia se constituyeran en mediación eficaz para la transformación interior de los hombres. Por dos veces consecutivas el starets ordena al discípulo Aliosha Karamazov -por entonces novicio, en su monasterio- cumplir el voto monacal en el espacio enfermo del mundo:

- Z - .. en cuanto Dios me llame a sí ... vete del monasterio, no es este tu lugar..." (37)

- Z - .. a ti Aliosha, muchas veces te he bendecido mentalmente en mi vida por tu rostro, sábelo ... Pienso de ti esto: te irás de estos muros, pero en el mundo vivirás como un monje. Muchos enemigos tendrás, pero tus enemigos mismos han de amarte. Muchas desdichas te traerá la vida, pero con ellas tú serás feliz, y la vida bendecirás y a los otros obligarás a bendecirla... Esto es lo principal" (38).

El núcleo de meditación que vincula ambos relatos está explícito en el texto evangélico citado por el padre Zósima: "En verdad, en verdad os digo que si el grano de trigo cayese en la tierra y no muriese, el solo quedará; mas si muriese, mucho fruto lleva". La piedad extrema de Mischkin se trasforma para la existencia de Aliosha en vocación crística destinada originariamente por el dolor a la Alegría.

(36) DOSTOIEVSKI, F. O.C., II, pp. 962-963; 1218-1255; ;363-1369.

(37) DOSTOIEVSKI, F. O.C., I, 894.

(38) DOSTOIEVSKI, F. O.C., I, p. 1037. 
Markel, el joven hermano muerto de Zósima, e Iliuscha tienen en común un hondo amor por la vida, por todas y cada una de las criaturas amadas por Dios, por la celebración permanente de la Gloria del Padre en la modesta existencia de cada ser, splendor mundi. Por eso Markel pide perdón a los gorriones, los más pobres entre los pájaros, e Iliuscha encomienda a su padre que arroje sobre su tumba algunas migas de pan, para que los gorriones le hagan compañía. Y lo que ambos nos dejan, cada uno en su modalidad: uno, en la Alegría anticipada; el otro, en la nostalgia de los afectos de este mundo, es el misterio profundo de una existencia que crece humanamente solo cuando el Amor la funda y la sostiene, una existencia que puede siempre elegir la estela luminosa de la luz para los caminos del hombre. La violenta, sensual, criminal historia de los Karamazov se cierra, precisamente, con las palabras de Aliosha al grupo de niños al despedir a Iliusha en su lecho postrero::

"Recordaremos su cara, su traje, y sus pobres botitas, y su féretro, y a su desventurado y pecador padre...

$\ldots$

Lo primero que haremos será tenerlo presente para toda la vida... puede que no entendáis lo que os estoy diciendo, pues muchas veces hablo de un modo incomprensible..., pero habéis de saber que nada hay más de elevado fuerte y sano, ni más provechoso para el ulterior curso de una vida, que un buen recuerdo, especialmente los que arrancan de la infancia y de la casa paterna... un recuerdo así de bello, así de santo..." (39).

\section{LA EXPERIENCIA DE LA BELLEZA}

En dos de sus obras cumbre: El Idiota y Los hermanos Karamazov, en situaciones argumentales decisivas, Mischkin y el staretz Zósima afirman su convicción de que "sólo la belleza salvará al mundo". En una narrativa como la de Dostoievski en donde el mal aparece como el núcleo invasor de la existencia del hombre moderno en una diversidad de estratos sociales, caracteres y modalidades, pero en la cual emergen, al mismo tiempo, personajes y situaciones -como el príncipe Mischkin, Aliosha Karamazov, Iliusha, Marckel, y el grupo de niños que invariablemente los rodea- que constituyen pequeños pero importantes islotes de luminosidad candorosa; y si, como se recuerda, el rasgo más propio del autor ruso es su religiosidad originaria que lo lleva naturalmente a reconocerse real y ficcionalmente con el pueblo ruso en la instancia del presidio. Y si, además, se tiene en cuenta que esta religiosidad es inicialmente cósmica -téngase presente el ámbito natural y contemplativo que junto a la pureza infantil hizo posible la curación inicial de Mischkinpero, a la vez, profundamente crística, no sorprende que tal belleza se encuentre en el relato dostoievskiano al menos en dos instancias netas: los islotes de luminosidad candorosa a los que aludimos antes, y, paradójicamente, en el punto de máxima abismación del hombre en el mal, punto en el que se decide la humanidad personal,

(39) DOSTOIEVSKI, F. O.C., II, 1368-1369. Ver asimismo el texto que cierra este aparato a p. 25 
única de cada hombre, su renovación o su pérdida definitivas, retrogradando el hombre -de cumplirse esta última- a instancias prehumanas y, más aún, demoníacas. Se ha intentado mostrar, hasta aquí, la presencia de ambas instancias como constitutivos del relato dostoievskiano; conviene ahora señalar el vínculo profundo entre ambas manifiesto en toda su dimensión en una experiencia de la belleza, que es, ante todo, terribilidad y otredad, honda y vertiginosa conmoción hacia un límite que abre en disyunción sin alternativas hacia la renovación o la alienación.

Lo primero que parece oportuno recordar es la proyección autobiográfica en toda la obra del escritor ruso, particularmente en aquellos momentos decisivos de su vida: su búsqueda de justicia a través de un ideal de fraternidad entre los hombres que lo lleva a una primera etapa de socialismo-progresista; en segundo lugar, su experiencia capital de acusación, condena y encarcelamiento durante cuatro años en los que se va labrando, en su corazón, junto a la identidad cada vez más intensa con su propio pueblo, el tránsito de una religiosidad hondamente cósmica a un cristianismo que lo confirma en la existencia del mal en el mundo como una amenaza latente a la cual el hombre deberá enfrentarse si quiere iniciar el camino de su verdadera salvación. Pero enfrentar el mal -he aquí el esfuerzo y la tragicidad de su fenomenología del mal- es asumirlo en toda su densidad y consecuencias. Es manifiesto que el modelo crístico del inocente que sin trazo alguno de pecado se ofrece en remisión de todos los pecados de la humanidad va cobrando en Dostoievski el peso de una experiencia masiva; y, por último, el hecho decisivo para su vida toda, y en consecuencia para su escritura, de la experiencia de horror de una condena a término suspendida momentos antes de su ejecución, experiencia límite en la que el tiempo humano alcanza dimensión destinal y comienza a valorarse en términos de eternidad.

El siguiente texto deja ver hasta qué punto estas experiencias de descenso configuran en el hombre y el escritor Dostoievski un modo de conocimiento de sí y del pueblo ruso:

"Incluso en el presidio, entre criminales, durante esos cuatro años pude, finalmente distinguir a la gente. ¿Lo creerás? Hay caracteres profundos, fuertes, magníficos y icuánta alegría me proporcionaba encontrar oro bajo una ruda corteza! [...] ¡Cuántos tipos de caracteres de la gente de pueblo he sacado del presidio! Me compenetré con ellos y por eso, me parece, los conozco suficientemente bien [...] Qué gente tan maravillosa. En general, el tiempo no ha pasado en vano para mí. Si no fue Rusia lo que conocí, en cambio sí he conocido al pueblo ruso y lo he conocido tan bien como muchos, quizá, no lo conocen" (40).

Muchos son los pasajes que en la obra de Dostoievski ilustran las dos instancias contrapuestas señaladas arriba, ambas como promesas salvíficas: por un lado, la de una sociedad futura construida desde ideales abstractos y utópicos que, al formularse, colocan al hombre singular, a la persona que es cada quien, en un doble discurso que termina por anularlo en nombre de ideales de justicia y solidaridad

(40) DOSTOIEVKSKI, F. Cartas a Misha (1838-1864), introd., trad. y notas de Selma Ancira, Barcelona, Grijalbo-Mondadori, pp. 167-168. 
superiores; y, por otro, la figura crística representada en algunos personajes prerrogativos en quienes el candor y la inocencia los distingue con dos rasgos esenciales: la piedad o compasión por todo sufrimiento humano y el acto de caridad que los lleva hasta la inmolación (41). Son estos rasgos los que hacen posible que estén en este mundo no perteneciendo totalmente a él. El máximo candor de Mischkin, Iliusha y Markel los conduce, necesariamente, por diversas vías, al abandono de este mundo, cumpliéndose, sin embargo en los tres, el acto de caridad crística. El caso de Aliosha Karamazov abre a un itinerario de la belleza-bien a desarrollarse dentro del mundo, una vocación monástica que lo expone al mundo en donde lo espera la dura misión de ayudar a los hombres a encontrarse en la Verdad de su vida ordinaria porque de ese modo ellos se reconciliarán, y -le advierte Zósima- "la vida bendecirás y a los otros obligarás a bendecirla".

Es manifiesto que el destino de Aliosha es el de un monje en el mundo, es decir de alguien que recuerda por su sola presencia y sus actos "que es de otro mundo", y que en eso consiste el sentido más hondo de su existencia: en recordarle al hombre que su vida no le es propia y que debe, en consecuencia, vivirla como una gracia cumplida en toda su dimensión.

Ahora bien, existen ciertamente otros personajes en los que la inocencia se muestra mucho más expuesta, si pudiera hablarse así, en su combate con el mal. Tomaremos como figura emblemática de esta estirpe al personaje de Sonia Simonovna Marmeladova. Se trata a los ojos de su padre de "una muchacha tierna y dulce, rubia y de hermosa cara triste" (42) quien, conociendo el alcoholismo de su padre sabe que "mientras más beb[e] más sufre y que "bebe para sufrir más profundamente" de aquí que cuando este le va a pedir dinero su respuesta inmediata, sin reservas es la compasión:

"Ella me dio treinta hopecks, los últimos, todo lo que tenía: lo vi con mis propios ojos. Ella no me dijo nada, se limitó a mirarme en silencio... Fue una mirada que no pertenecía a la tierra sino al cielo. Sólo en el cielo se puede sufrir por los hombres y llorar por ellos sin condenarlos... Porque quién puede apiadarse de alguien como yo?...

(41) Un desarrollo interesante, desde el punto de vista literario, es presentado por George Steiner en su Tolstoi o Dostoievski, México, Siruela, 2002, Col Biblioteca Ensayo. Ofrecemos al lector interesado dos breves textos que contrastan nuestra hipótesis de manera negativa el primero, de manera coincidente el segundo. Ambos muestran, por otra parte, los matices del talento de Steiner en el trabajo hermenéutico: "El crimen de Mishkin consiste en el exceso de compasión más allá del amor, pues así como hay una ceguera de amor (El rey Lear), hay también una ceguera de piedad". (ed. cit IV, p. 178). El segundo texto refiere a la escena en que los cien mil rubros de Rogozhin son arrojados al fuego, cuando Nastasia parte junto a Rogoshin hacia su muerte. Steiner contrasta dos hipótesis: "'Vamos Rogozhin! Adios, príncipe. He visto al [un] hombre por primera vez en mi vida'. Esto incluye un sentido aceptable: Nastasia rinde homenaje al príncipe Mishkin; comparados con él, los otros seres humanos le parecen brutos e incompletos. La otra interpretación (que me sugirió un erudito ruso) ofrece explicaciones más ricas y pertinentes. En aquella espeluznante noche, Nastasia ha visto literalmente al hombre por primera vez, ha presenciado extremos de nobleza y de corrupción; se le ha mostrado adónde (sic) puede llegar la naturaleza humana". Steiner, ed. cit., III, p. 175.

(42) DOSTOIEVSKI, D. Crimen y Castigo, p. 27. 
-Pero ¿por qué alguien tendría que sentir compasión? -preguntó el tabernero, acercándose a Marmeladof.

....

-¿Que por qué tendría alguien que sentir compasión? -gritó de pronto Marmeladof... Es verdad: no merezco que nadie me tenga compasión; lo que merezco es más bien que me crucifiquen. ¡Sí, sí, la cruz, no la compasión...! ¡Crucifícame, Juez! ¡Y al crucificarme ten piedad del crucificado! Yo mismo caminaré al suplicio porque tengo sed de dolor y de lágrimas ... Pero nosotros no podemos recibir piedad sino de Aquel que es piadoso con todos los hombres, de Aquel que todo lo comprende, del único, de nuestro único gran juez. Él vendrá, vendrá el día del juicio y preguntará: “¿Dónde está esa joven que se sacrificó por una madrastra tísica y cruel y por unos niños que no son sus hermanos de sangre? ¿Dónde está esa joven que tuvo piedad de su padre y no despreció con horror a ese bebedor despreciable? Y Dirá a Sonia: "Ven. Yo te perdono... te perdono... y ahora te redimo de todos tus pecados porque tú amas mucho" (43).

El texto es relevante porque está ubicado en las primeras páginas de Crimen y Castigo, de manera que la belleza de la muchacha abre el espacio argumentativo de la novela mientras que el mensaje crístico será develado solo al final, como descubrimiento. En efecto, las palabras del padre de Sonia dejan ver la consistencia entitativa de la experiencia de la belleza de esta mujer: belleza física e interior de una joven a quien la miseria del mundo ha arrojado a la mayor tristeza, pero en quien el núcleo celeste de su humanidad no ha sido obliterado: ante el sufrimiento del otro, ella no juzga, acoge, acompaña, compadece. En este texto -que se encuentra en las primeras páginas de un relato que alcanza casi las quinientas- el escritor sintetiza en una rápida pero profunda pincelada la totalidad del itinerario de Rodian Raskolnikov quien comienza en sus ideales de utopía y orgullo infatuado, se arroja al crimen como un desafío probatorio de su superioridad sin sospechar la carga de culpabilidad que esa experiencia desencadenaría en su corazón, y concluye en lento, doloroso reconocimiento de sí a través de su aislamiento en la prisión y del desprecio consecuente de sus compañeros de celda que ven en él a un ateo, un hombre extraño que no los trata. que los ignora -la mentada fraternidad utópica se desploma estrepitosamente- y finalmente, la emergencia de un sentimiento cierto, desconocido, de amor hacia Sonia a quien, sin embargo, antes de su entrega, había pedido que no lo abandonara. El clamor caritatis emerge límpido en su corazón, y, derribando anclajes recónditos de un idealismo pseudointelectual, hace espacio para su verdadera y final conversión.

La belleza de la que habla Dostoievski es, sin duda, la belleza crística, aquella que irrumpe por obra de la Gracia en el denudamiento de la Cruz, ya que al dolor de toda Cruz sigue el escándalo de la inocencia que ella misma devuelve. Uno de los textos más hermosos del Idiota entrega esta concepción de la Belleza desde un modelo icónico intratextual que recrea en la figura de Cristo el pensamiento de la creación en el Padre y, su necesaria kénosis en el Hijo;

(43) Ibídem, pp. 31-32. 
"Los artistas pintan siempre a Cristo según las historias evangélicas; yo lo pintaría de otro modo: lo representaría solo, que alguna vez lo dejarían solo sus discípulos. Únicamente dejaría con él a un niño pequeño. El niño jugaría a su lado; quizá le estaría contando algo en su infantil lenguaje, Cristo le ha escuchado, pero en este momento medita; su mano involuntariamente, por olvido, ha quedado en la rubia cabecera del niño. Mira hacia la lejanía, hacia el horizonte; un pensamiento grande como el mundo entero, se sustenta en su mirada; su faz es triste. El niño ha callado, se le apoya de codos en las rodillas, y, con la mejilla en su pequeña mano, levantada la cabeza, se le queda mirando fijamente, pensativo, como pensativos se quedan a veces los niños. El sol se pone ... ¡Este sería mi cuadro! (44).

\section{CONLUSIONES}

El genio de Dostoievski consiste en develar, a lo largo de toda su narrativa, la terrible y larvada presencia del mal en la existencia humana, bajo una diversidad de experiencias destinadas todas a mostrar el riesgo constante de desfiguración de la faz humana. La urgencia y tragicidad de su voz provienen de las exigencias de una época culturalmente volcada a un materialismo progresista cuyas propuestas alejan al hombre de toda preocupación por su destino como persona, separándolo así de toda búsqueda de sentido. El escritor ruso se adelanta, indudablemente, al grito trágico de F. Nietzsche de la muerte de Dios y el abandono definitivo del hombre sobre esta tierra.

Todas y cada una de sus páginas reiteran el dolor humano, lo vuelven írrito, lo extreman en sus posibilidades de manifestación expresando la permanencia en él -y en consecuencia en todo hombre- de la búsqueda de un camino, del deseo de retorno hacia un lugar de infancia cuya existencia real la razón moderna se empeña en negar. De aquí sus grandes enfermos de lesa humanidad, sus endemoniados criminales y suicidas que sólo buscan la probatoria de su voluntad de poder, sin olvidar de mostrar no obstante en el fragor de este infierno la presencia silenciosa, paradójica, contradictoria las más de las veces, de rostros inalterados por el dolor y transidos de una inocencia de otro mundo, un espacio sacro que anuncia a los hombres que la familia humana es posible, que la creación del hombre y del mundo es incoativa y que su Gracia profunda y misteriosa consiste en devenir Gloria ya en esta tierra. Para decirlo con la hermosa expresión de George Steiner (45), F. Dostoievski apuesta a la presencia real, al hondo sentido del mundo como Palabra.

(44) Citado por Jorge MORILLAS, "La imagen de Cristo en Dostoievski” en Espíritu, año LI (2002) 126, p.295 (El Idiota, trad. de José Laín Entralgo, Círculo de Lectores, 1972, pp. 468-469).

(45) Aludimos a la primera página de Presencias Reales, Bs. As., Espasa Calpe, 1993, p.13, en donde Steiner denuncia el deconstruccionismo epistemológico y cultural de F. Nietzsche y anuncia su ya clásica meditación sobre la literatura como afirmación, contraria a Nietzsche, del sentido verdadero, real, de las creencias más hondas del hombre como estructurantes precisamente de su humanidad. El punto es importante si se recuerda el agnosticismo declarado reiteradas veces por el crítico y filólogo aludido. 


\section{RESUMEN}

La obra de F. Dostoievski se estudia en este trabajo con el propósito de discernir los estratos y/o configuraciones narrativos que actualizarían la, aún hoy, enigmática frase con la que se lo identifica: la Belleza salvará al mundo. El desarrollo sigue tres umbrales de aproximación sucesivos: ante todo, el desglose de una fenomenología del mal evidente en la obra; luego, el reconocimiento de ciertos núcleos de luminosidad que emergen como islotes u oasis aparentemente lejanos, separados casi argumentativa y narrativamente de aquel horizonte inicial; sigue, finalmente, el estudio del vínculo significativo existente entre ambos. En este último punto se advierte que la presencia de estos islotes de luminosidad -amplificaciones o historias incluidas "no pertinentes"- configuran, no obstante, la vía regia de una intencionalidad significativa teológico-existencial que privilegia la conmoción del relato a la lógica de la discursividad.

\section{ABSTRACT}

This article studies F. Dostoyevski's work with the purpose of discerning the narrative strata and/or configurations that actualize the phrase, enigmatic even today, with which it is identified: Beauty will save the world. The development of this article follows along three thresholds of successive approximation: above all, the distilment of a phenomenology of evil, evident in the work; then, the recognition of certain nuclei of luminosity that emerge like small, apparently distant islands or oases separated almost argumentatively and in a narrative manner from that initial horizon; and finally followed by the study of the existing significant link between the two. In this last point the presence of these islets of luminosity is regarded -"non-pertinent" amplifications or stories included- as, nevertheless, configuring the royal road of a theologicoexistentially meaningful intentionality that privileges the upheaval of the story over the logic of its quality of discourse. 
